Precipitin tests with anti-horse globulin sera showed certain differences-increased flocculation time, decreased precipitability and changed optimum proportions-compared with the original protein. These differences might be due to loss of bound carbohydrate or to slight proteolysis, but they seem small in consideration of the extensive treatment of the protein and the considerable change of carbo. hydrate content.

These results, repeated on several samples of protein, suggest that the part of the carbohydrate removed may not be important in determining the properties of serum pseudoglobulin.

I am grateful to Prof. J. R. Marrack for the precipitin tests, to Mr. E. R. Holiday for measuring the ultra-violet absorption and to Mr. J. St. L. Philpot for measuring the ultra-centrifugal sedimentation.

Research Laboratories,

\section{Alexander G. OGston.}

London Hospital, E.1. May 10.

${ }^{1}$ Biochem. Z., 260, 247 (1933).

\section{Schütz's Law and the Clotting of Blood}

IT seems worth while to point out a misunder. standing of Schütz's law, which has been found in works on blood clotting, and which has been accepted in reviews on this subject, ${ }^{1,2}$.

Fuld $^{3}$ (cf. later Tsunoo ${ }^{4}$ ) first applied Schütz's law to the clotting of blood plasma. Now, the results obtained by Schütz ${ }^{5}$ show that the amount of albumin digested in a given time is proportional to the square-root of the amount of enzyme, that is,

$$
[P]=\text { const. } \times \sqrt{[\bar{E}]} .
$$

In Schütz's law the reaction time $t$ does not appear as a variable, and so the law cannot, of course, be used for the characterization of time relations. In blood-clotting, $t$ and $[E]$ are the only measurable quantities, while $[P]$ is constant, and it follows that the original law of Schütz is of no value in these circumstances. To extend the formula, $t$ must be incorporated, based upon experiments, and in this way Arrhenius ${ }^{8}$ obtained the equation :

$$
[P]=\text { const. } \times \sqrt{[\bar{E}] \cdot t}
$$

but this is not the law used by Fuld ${ }^{3}$. The rule referred to by Fuld as Schütz's law can be formulated as

$$
\frac{1}{t}=\text { const. } \times \sqrt{[E]},
$$

and on comparing (3) with (1), it appears evident that an incorrect use of $[P]$ and $1 / t$ as interchangeable measures of reaction velocity has led to this mis. understanding. Bodansky ${ }^{7}$ has recently shown similar confusions to exist in general in enzyme chemistry.

A detailed study on the clotting time of blood is to be published soon.

Biological Institute,

Tage Astrup.

Carlsberg Foundation,

Copenhagen. May 11.

' Hammarsten, O., "Lehrbuch d. Physiol. Chem.", 204 (1926).

' Wöhlisch, E., Ergeb. Physiol., 28, 571 (1929).

${ }^{3}$ Euld, E., Hofmeisters Beitr. chem. Physiol., 2, 514 (1902).

- Tsunoo, S., Pflikgers Arch., 210, 334 (1925).

s Schütz, E., Z. physiol. Chem., 9, 577 (1885).

"Arrhenius, S., "Immunochemie", 44 (Leipzig, 1907).

'Bodansky, O., J. biol. Chem., 120, 555 (1937).

Cancers of Infancy and Anærobic Glycolysis

CRAMER ${ }^{1}$ has directed attention to the fact that the retinoblastoma, which appears almost exclusively in infants, and the chorion-epithelioma arise from tissues that have a type of metabolism resembling that of tumours.

Besides the retinoblastoma, the neuroblastoma and nephroblastoma are also tumours of the first few years of life, and in recent years it has been shown that brain and kidney medulla ${ }^{2}$ have a high glycolysis. Thus these tissues also have a metabolism resembling that of embryo and of tumour, and this may have some connexion with the occurrence of these tumours in the early years of life. Whether the nephroblastoma arise from the medulla of kidney is doubtful, but in my opinion these relations are of the utmost importance and should be borne in mind by pathologists and workers who hope to unravel the causative mechanism of cancer.

It is irrational to work on the hypothesis that cancer afflicts cells and tissues of all ages through the same mechanism, when the cancers of infancy may constitute a separate category by virtue of the peculiar metabolic properties of the tissues of their origin.

Department of Physiology,

University of the Witwatersrand,

Johannesburg. April 28.

1 Cramer, Cancer Review, 348, 354 (1928).

${ }^{2}$ Dickens and Weil-Malherbe, Biochem. J., 30, 659 (1936).

\title{
Dissolving Action of Micro-Organisms on Milk-Wool
}

IN Nature of April 9, Prof. Jan Smit and B. Van der Heide gave the results of some work which they have carried out on the action of microorganisms on milk-wool. This communication was brought to the notice of Messrs. Snia-Viscosa, of Milan, the manufacturers of, and Comm. Ferretti, the inventor of, "Lanital", the trade name given to the so-called casein or milk-wool made by the Ferretti process. In reply, they state that although "Lanital" has been in commercial use for some years, no case of attack of "Lanital" by micro-organisms has come to their notice; on the contrary, it is found that whereas wool is attacked by moths, "Lanital" is not.

Messrs. Courtaulds, Ltd.,

W. H. Glover.

Coventry. May 16.

\section{Synthesis of $\alpha$-Tocopherol (Vitamin E)}

WE have described ${ }^{1}$ the synthesis of a compound, obtained by letting phytyl-bromide react with trimethyl-hydroquinone. We also expressed the opinion that this substance might be the racemic form of $\alpha$-tocopherol.

In the biological test this compound gave excellent vitamin- $E$ activity in doses down to $6 \mathrm{mgm}$., the smallest tested so far. By means of brom-camphor sulphonic acid, the racemic compound can be split up into the optically active forms. The brom. camphor sulphonate of the synthetic compound shows the same melting point as the corresponding $\alpha$-tocopherol derivative $\left(48-50^{\circ}\right)$, and mixed together there is no depression. The optical activities are identical : $[\alpha]_{D}=+30^{\circ}\left( \pm 2^{\circ}\right)$ in alcohol.

Chemisches Institut

der Universität, Zürich. May 13.

${ }^{1}$ Helv. chim. Acta, 21, 520 (1938).
P. KarRer.

H. Fritzsche.

B. H. RINGIER.

H. SALOMON. 